\title{
Micro-Climatic Amelioration in a California Desert: Artificial Shelter Versus Shrub Canopy
}

\author{
Nargol Ghazian ${ }^{1 *}$, Mario Zuliani' ${ }^{1}$ and Christopher J. Lortie ${ }^{1,2}$ \\ 1 Department of Biological Science, York University, 4700 Keele St, Toronto, ON M3J 1P3, Canada \\ 2 National Centre for Ecological Analysis and Synthesis (NCEAS), 735 State St \#300, Santa Barbara, CA 93101, \\ United States \\ * Corresponding author's e-mail: nargolg1@my.yorku.ca
}

\begin{abstract}
Anthropogenic factors such as climate change, land use, urbanization, alongside the spread of invasive species are some of the challenges impacting the arid and semi-arid regions globally. The canopy of many native plants including shrubs and trees not only provides refuge from predators for some animals but also offers a shelter from climatic stressors for other plants. The canopy of native vegetation can thus be a microhabitat critical to the persistence of many species locally, and it is vital to better understand its importance for the conservation and recovery of species in these landscapes. In this study, we tested the hypothesis that triangular and rectangular artificial canopies function similarly to the canopy of resident native shrubs when ameliorating the understory micro-climate. Three light permeabilities including $15 \%, 50 \%$, and $90 \%$ were tested by measuring soil and air temperature with light relative to paired open gap (non-canopied) microsites and shrubs. Shelters offered more stable temperatures and reduction in light compared to the open gap and were not significantly different from established native shrubs. This suggests that this simple, affordable intervention can provide a stop-gap solution that approximates natural heterogeneity in climate at fine scales and offers a refuge whilst managers and stakeholders restore native vegetation such as slow-growing and difficult to establish shrubs within this ecosystem.
\end{abstract}

Keywords: climate change, micro-climate, temperature, solar radiation, shelter, conservation, restoration.

\section{INTRODUCTION}

Climate change in arid and semi-arid regions is a critical issue globally. The rate of anthropogenic climate change is rapidly increasing in deserts and semi-arid grasslands (Williams 2014) and species need to adapt through many strategies. These changes in drylands in turn precipitate extensive ecological shifts including species loss (Barrows 2011), range shifts (Bachelet et al. 2016), change in interactions (McCluney et al. 2012), increased invasion by exotic plants (Abatzoglou and Kolden 2011), and additional stress on resident species in these harsh environments (Finch 2012). Factors such as land-use changes including agriculture in drylands (Germano et al. 2011; Eliason and Allen 1997) can further decrease biodiversity by reducing the available terrestrial habitat for plants and animals (Nopper et al. 2018; Irwin et al. 2010; Elmqvist 2013). Furthermore, vegetation such as shrubs and other foundational plants are often removed or impacted (Sankey et al. 2012). In deserts, animals will not only experience large-scale changes such as drought, but also small-scale changes such as relatively more extreme fluctuations in abiotic factors such as temperature (Shrode and Gerking 1977; Hadley 1970). Deserts are getting hotter (Allen et al. 2014; Nabhan 2013) and long-term mega-droughts in some regions are relatively more frequent (Guerreiro, Kilsby, and Fowler 2017; Kogan and Guo 2015). This evidence suggests that not only do gross-scale changes in climate exert pressure on communities and sensitive species in drylands, but fine-scale changes and fluctuations can potentially further exacerbate 
local extirpation events (Olden, Poff, and Bestgen 2008), if not extinction (Munguia-Vega et al. 2013). Consequently, refuges, shelters, vegetation, or other attributes in the landscape are likely to enable persistence with changing climate through providing a buffer through variation by reducing the amplitude of variation.

Vegetation is a key aspect of most landscapes in drylands. Mechanistically, different types of vegetation are important for soil water retention as they could lead to different soil bulk densities in drylands (Wang et al. 2013). Shrubs are the dominant vegetation in deserts (Miriti, Joseph Wright, and Howe 2001; Throop et al. 2012). Shrub species can thus be used to examine climate change impacts and strategies used by associated plants and animals to adapt or respond to variation at fine-scales (Sotomayor and Drezner 2019). Foundation shrubs are able to facilitate other taxa through various mechanistic pathways that include, but are not limited to, seed trapping, abiotic stress amelioration, herbivore protection, increasing pollination services, facilitation-mediated secondary seed dispersal, and soil modification (Filazzola and Lortie 2014; Lortie, Filazzola, and Sotomayor 2016). An important agent of structural facilitation is the shrub's canopy (Filazzola et al. 2017). Canopy micro-climates are generally cooler, more humid, and experience lower solar radiation compared to the open sites (Filazzola et al. 2017; Holzapfel and Mahall 1999). Shrubs fulfill a critical role; hence, more species are associated with shrubs than open spaces (Lortie, Filazzola, and Sotomayor 2016; Flores and Jurado 2003). shrub canopies provide great benefits but can vary in extent that they filter or dapple light (Sonnentag et al. 2007; Brantley and Young 2010), which likely influences the extent to which they cool the understory. Structural diversity alongside species diversity is crucial to many landscapes (Brooks 1999; Cowling et al. 1999; Morris 2000). Shrubs help increase structural diversity; hence, it is important to include them in the dialogue when discussing the impacts of anthropogenic changes on the landscape.

Heterogeneity in micro-climate and habitat at fine-scales is important of the maintenance of biodiversity. California is home to a diversity of dryland landscapes, dominated by many species of shrubs (Stuart and Sawyer 2001). Ephedra Californica (Mormon Tea) is a common foundation shrub species that benefits other plants (Lortie et al. 2018) and animals (Ivey et al. 2020).
Shrubs provide a key component of this variation in many systems, including deserts (Fuhlendorf et al. 2017; Thorhallsdottir 1990). Hence, it is vital to advance the theory and application by A) testing shrubs as a thermal shelters and sources of fine-scale heterogeneity relative to open gap microsites, and B) directly test small, shrub-sized shelters both as a mean to more directly explore canopy effects without the biotic components of vegetation including litter, soil effects, or roots, and to examine a simple solution that can promote micro-heterogeneity in deserts and provide temporary structural diversity. Furthermore, it is important to direct and sample value of more shelters in some dryland systems as a form of thermal refuge and alternate modes of conservation whilst landscape recovery is made and new shrubs are grown.

Shrubs can be both keystone and foundation species in deserts. A keystone species (predator) is one that generally occurs in low abundances and occupies a high trophic level, but controls the density and diversity of other ecologically significant species (Mills and Doak 1993). On the other hand, a foundation species is locally abundant, common, and occupies a lower trophic level; yet, they also create locally stable conditions required by other species (Attum and Eason 2006). Foundation shrubs in dryland systems are typically slow-growing (Sawyer, Keeler-Wolf, and Evens 2009), difficult to establish in areas impacted by climate change (Meyer and Pendleton 2005), and frequently cleared by ranchers for livestock farming (Webb and Stielstra 1979). Hence, it would be ideal to have the capacity to mimic shrubs to augment and enhance low shrub cover areas and serve as stop-gap tools for conservation. Artificial canopies can provide an important surrogate test for canopy effects in drylands and there is a relatively long history of their use in ecology. Rainout shelters/drought nets and Open-TopChambers (OTC) have been used to study the change in a variety of abiotic parameters such as $\mathrm{CO}_{2}$, temperature, soil temperature, solar radiation, and humidity (Yahdjian and Sala 2002; Marion et al. 1997). Although these shelters are effective, they can be expensive to build and may be difficult to assemble in a short period of time. Rainout shelters/drought nets used in semi-desert grassland studies have proven to be effective in altering precipitation, yet they have minimal impact on changing other variables such as air and soil temperature, humidity, and light (English et 
al. 2005; Gherardi and Sala 2013). On the other hand, OTCs have been experimentally used to increase temperature in plant studies in high-latitude ecosystems (Marion et al. 1997). Although these shelters are effective at manipulating different abiotic parameters, they are typically larger in size (not shrub-sized). Additionally, large-scale solar farms can increase rain and vegetation (Li et al. 2018), but lead to habitat fragmentation thus limiting movement (Lovich and Ennen 2011). It is therefore key to take advantage of the variability in temperature and light in drylands to explore the effects of artificial shelters that are inexpensive and easily-built, which most importantly do not limit movement like solar farms or giant deploys, and help increase heterogeneity/open gaps that can be key to many animals.

Microsite heterogeneity through shrubs for climate is relatively novel concept for restoration and management, and provides an excellent framework to explore experimentally. Using a California desert ecosystem, we examined the hypothesis that artificial shelters can mimic the micro-climate of shrub canopies. The following predictions were tested: 1) Shelters are consistently cooler than open gap and not significantly different from shrub canopies, 2) shape of artificial shelters and UV permeability will shift light and temperature regimes- this is ecologically similar to light dappling effects of shrubs, 3) shelters have relatively lower variation in micro-climate in comparison to the open gaps, and 4) micro-climatic variation at these scales differs from similar sensors at weather stations. A deeper understanding of these physical structures impacts with and without other effects of living vegetation at finescales is important to better understanding habitat in deserts.

\section{MATERIALS \& METHODS}

\section{Study site}

This study was conducted in Panoche Hills Management Area located on the western edge of the San Joaquin Valley, California (Bureau of Land Management; $36^{\circ} 41.78^{\prime} \mathrm{N}, 120^{\circ} 47.89^{\prime} \mathrm{W}$ ) (S; Supplementary Appendix). The regional climate can be characterized as arid/semi-arid. The average annual precipitation is $25.5 \mathrm{~cm}$ with an annual low and high temperature of $10.4{ }^{\circ} \mathrm{C}$ $\left(50.72{ }^{\circ} \mathrm{F}\right)$ and $24.6{ }^{\circ} \mathrm{C}\left(76.3^{\circ} \mathrm{F}\right)$, respectively
(Filazzola et al. 2017). Winter and fall are considered to be the wettest seasons. The mean temperature observed in May is $20.4{ }^{\circ} \mathrm{C}\left(68.72{ }^{\circ} \mathrm{F}\right)$ and $23.7^{\circ} \mathrm{C}\left(74.66^{\circ} \mathrm{F}\right)$ in June (Los Baños Weather Station, http://www.usclimatedata.com/). The area is an Ephedra californica parkland, spread randomly between invasive grasses including Bromus madritensis ssp. Rubens, Bromus hordeaceus, Erodium cicutarium and Schismus barbatus (Filazzola et al. 2017). The study took place between May 20th to June 12th, 2019.

\section{Microsite deployments}

Shelters were constructed using PVC piping and UV permeable shade cloths at three permeabilities including $15 \%, 50 \%$, and $90 \%$. The open gap at $0 \%$ light blockage served as the procedural control as the frame was still deployed. The cloths were attached to the PVC using zip ties (Figure 1). Table A (Supplementary Appendix) describes the number of pieces at specific dimensions and diameter needed to build each triangle or square shelter. There were six replicates of each shape. Two for each blockage percentage for a total of 12 replicates. Pipes were slid onto metal stakes and secured into ground for stability ( $\mathrm{J}$ and K; Supplementary Appendix). We selected a set of four microsites: shrub, open gap, square and triangle, and deployed all in the same area. Each microsite was geo-referenced (B; Supplementary Appendix). There were a total of 7 shrub-open pairs for a total of 14 microsites. Shrub canopy was measured at the $\mathrm{x}, \mathrm{y}$, and $\mathrm{z}$ plane where height (x) was the widest dimension of the canopy and perpendicular to the ground (Lortie et al. 2018). The open gap microsite was directly 2 meters away from the shrub at random orientation generated by a number table. The ground surrounding the shrub was mostly bare or contained patches of Bromus madritensis ssp. Rubens.

To measure the difference in light and temperature within canopied microsites and the open gap, Onset HOBO Temperature/Light Pendant (8K) loggers (Hoskin Scientific 2020) were placed inside and directly outside to the right of the microsites. Each pendant was tied to a plastic stake using a zip tie, recording data at 1 hour intervals. Stakes were hammered into the ground until stable with $\sim 10 \mathrm{~cm}$ remaining above ground. This was done to ensure that logger data were less-influenced by ground cover and true ambient conditions both inside and in the open were 
Table 1. Key contrast of abiotic measurements estimated using GLM for the study period. (May 20th to June 12th, 2019). Microsite/site and cover type were each treated as a factor. Significant P-values are in bold. See Methods for model fitting

\begin{tabular}{|c|c|c|c|c|c|c|}
\hline \multicolumn{2}{|c|}{ Measure } & \multirow[t]{2}{*}{$d f$} & \multirow[t]{2}{*}{$\begin{array}{l}\text { Deviance } \\
\text { Resid. }\end{array}$} & \multirow{2}{*}{$\frac{d f \text { Resid. }}{22583}$} & \multirow{2}{*}{$\frac{\text { Dev }}{10784021}$} & \multirow[t]{2}{*}{$\operatorname{Pr}(>C h i)$} \\
\hline \multirow{2}{*}{ Temperature } & NULL & & & & & \\
\hline & as.factor (microsite) & 5 & 74212 & 22578 & 10709809 & 0.0001 \\
\hline \multirow{2}{*}{$\begin{array}{l}\text { Solar Radiation/ } \\
\text { Intensity }\end{array}$} & NULL & & & 13253 & $6.42 \times 10^{11}$ & \\
\hline & as.factor (microsite) & 5 & $1.33 \times 10^{11}$ & 13248 & $5.09 \times 10^{11}$ & 0.0001 \\
\hline \multirow{4}{*}{$\begin{array}{l}\text { Temperature by } \\
\text { Blockage } \\
\text { (cover type \%) }\end{array}$} & NULL & & & 15388 & 7168340 & \\
\hline & as.factor (microsite) & 2 & 18912.1 & 15386 & 7149427 & 0.0001 \\
\hline & as.factor (cover type) & 3 & 16739.0 & 15383 & 7132688 & 0.0001 \\
\hline & $\begin{array}{l}\text { as.factor (microsite): } \\
\text { (cover.type) }\end{array}$ & 2 & 2370.6 & 15381 & 7130318 & 0.07755 \\
\hline \multirow{2}{*}{$\begin{array}{l}\text { Relative Interaction } \\
\text { Index (RII) }\end{array}$} & NULL & & & 61 & 0.025029 & \\
\hline & as.factor (microsite) & 2 & 0.0014171 & 59 & 0.023612 & 0.1703 \\
\hline
\end{tabular}

recorded. Air temperature $\left({ }^{\circ} \mathrm{F}\right)$ and light intensity (lum $\left./ \mathrm{ft}^{2}\right)$ were recorded hourly. Loggers were placed out mid-May and collected in mid-June to account for spring-summer seasonal variation.

Shelters were constructed on-site. Rectangular (commenly referred to as square) shelters consisted of two sides with two $61 \mathrm{~cm} 1 / 2$ inch pipes facing the ground connected to a $61 \mathrm{~cm} \mathrm{3/4} \mathrm{inch}$ pipe using a $90^{\circ}$ elbow. Triangular shelters were built using a $75 \mathrm{~cm} \mathrm{3/4}$ inch top pipe connected to a $1 / 2$ inch to $3 / 4$ inch adapter. The adapter was then attached to a $1 / 2$ inch 3-way $90^{\circ}$ elbow fitted with two $61 \mathrm{~cm} \mathrm{1/2} \mathrm{inch} \mathrm{pipes.} \mathrm{Shade} \mathrm{Cloths} \mathrm{were} \mathrm{used}$ to cover two sides of the triangular shelters and three sides of the rectangular shelters. The cardinal direction or orientation of each shelter was decided using a random number table and recorded. Shelters were inspected and repaired as needed throughout the study period.

\section{Macro-climatic climate estimates}

Hourly weather data were downloaded for the study site for the total duration of the study (Los Baños Weather Station at $37^{\circ} 03.30^{\prime} \mathrm{N}$, $120^{\circ} 51.00^{\prime} \mathrm{W}, \quad \mathrm{http}: / / \mathrm{www}$.usclimatedata.com/). Date, air and soil temperature $\left({ }^{\circ} \mathrm{F}\right)$ with solar radiation $(\mathrm{W} / \mathrm{m} 2$, converted to $\mathrm{lum} / \mathrm{ft} 2)$ were retrieved from this climate source, compiled, and published for re-use (Ghazian, Zuliani, and Lortie 2020).

\section{Statistical analyses}

All statistics were performed using $\mathrm{R}$ version 4.0.0 ( $\mathrm{R}$ Core Team 2020). Code is published on Zenodo (Ghazian 2020) and micro-climate data are published on Figshare (Ghazian, Zuliani, and
Lortie 2020). Q-Q plots were used to examine the distribution of data and to check for normality and homoscedasticity (Schützenmeister, Jensen, and Piepho 2012). The relationship between temperature and light intensity was examined using Kendall's rank correlation (non-parametric, continuous data). Generalized Linear Models (GLM) were used to compare temperature, light intensity, cover type, and microsite (Nelder and Wedderburn 1972). GLM dispersion parameters with AIC scores were used to compare and select the appropriate family to fit to models (Richards, Whittingham, and Stephens 2011). Temperature and solar radiation models were fit to Gaussian distribution. We explored spread in histograms by examining variance and used a Levene Test to check heterogeneity of variances for temperature and solar radiation across microsites (Schultz 1985). Post-hoc tests were done using the function emmeans from the emmeans $\mathrm{R}$ package (Lenth and Herve 2019). Relative Interaction Indices (RII) (Armas, Ordiales, and Pugnaire 2004) were used as an effect size measure to estimate the strength and direction of the microsite effect for temperature as follows:

$$
\mathrm{RII}=\frac{\mathrm{A}_{\mathrm{s}}-\mathrm{A}_{\mathrm{c}}}{\mathrm{A}_{\mathrm{s}}+\mathrm{A}_{\mathrm{c}}}
$$

where: $A_{S}$ and $A_{c}$ are the parameters for ambient temperature under the shelter or shrub and the paired open gap microsite. The index values range from -1 to +1 . For temperature, a positive value indicates that the shrub or shelter microsite is hotter relative to the open gap, or less ameliorated (Sotomayor and Drezner 2019). A value of 0 indicates a neutral effect. 


\section{RESULTS}

\section{Temperature effects}

Shrub and the open gap microsites were consistently the warmest (Estimated Marginalized Mean (EMM) $73.9 \pm 0.351^{\circ} \mathrm{F}$ and $73.7 \pm 0.219^{\circ} \mathrm{F}$, respectively), while the triangle and square microsites were the coolest (EMM $70.5 \pm 0.467^{\circ} \mathrm{F}$ and $72.7 \pm 0.378^{\circ} \mathrm{F}$, respectively) (Figure 1, Table 2). The triangular shelter was the only microsite significantly cooler than the open gap (F; Supplementary Appendix; post-hoc $\mathrm{p}=0.0001)$. Triangle was also significantly cooler than square $(\mathrm{F}$; Supplementary Appendix; post-hoc $p=0.0034$ ). This cooling effect was most pronounced under the $90 \%$ blockage (I; Supplementary Appendix; post-hoc $\mathrm{p}=0.0001)$. Moreover, triangle was also significantly cooler than the shrub microsites (F; Supplementary Appendix; post-hoc test, $\mathrm{p}=0.0001)$. The square microsite had the lowest EMM for RII $(-0.00308 \pm 0.00408)(H, Q$, and R; Supplementary Appendix). Higher maximum temperatures were more frequently recorded in the open gap microsites where relative variance was also the greatest (Figure 2, Table 3). We calculated the variance in temperature for each microsite, as well as for the weather-station data and found that they significantly differed (Figure 3, Table 3, Levene's F-Value $=60.096, \mathrm{p}=0.0001$ ). The lowest relative variance in temperature was observed at the weather station (Table 3), while the shrub had the highest variance of all canopied microsites (Table 3) followed by the open gap (Table 3). The lowest variance in temperature was seen under the square and triangle shelters
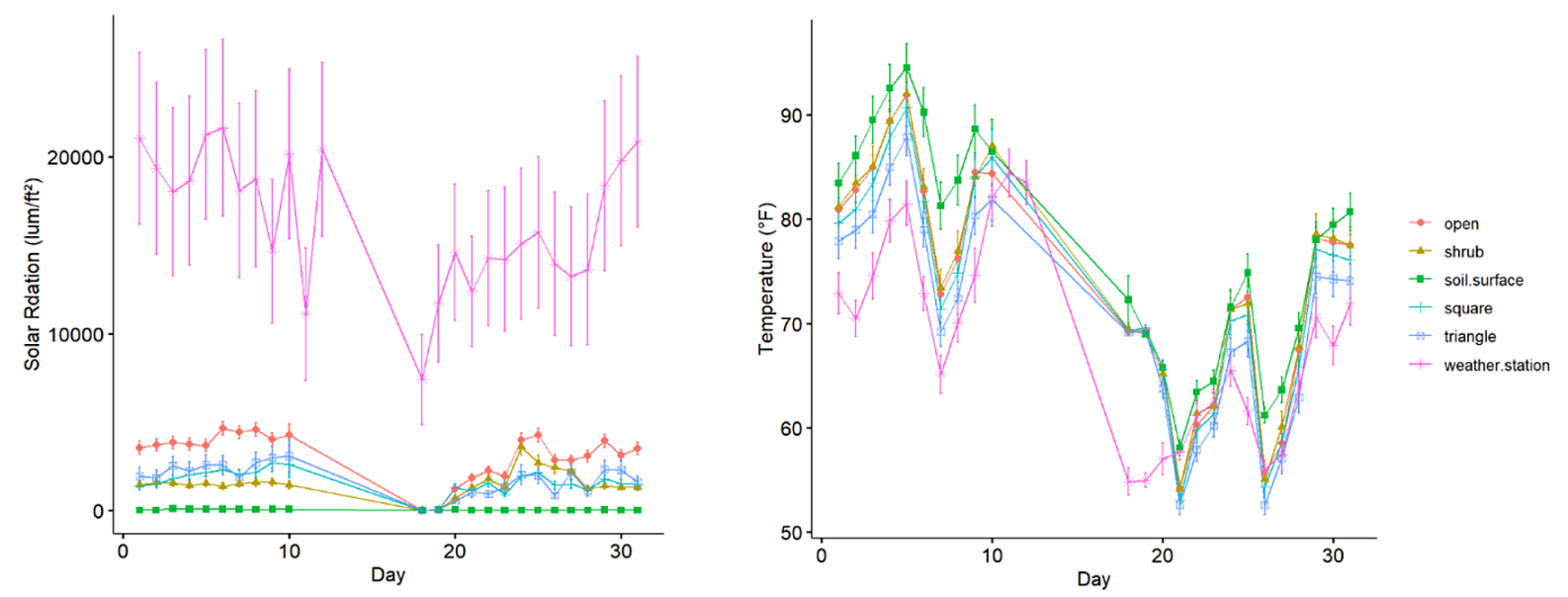

Figure 1. Mean daily temperature $\left({ }^{\circ} \mathrm{F}\right)$ and solar radiation (lum/ft2) over the course of 2019 spring-summer season recorded at each microsite using micro-loggers and retrieved from Los Baños Weather Station. Point shapes represent different microsites. Solid lines connect daily means. Errors bars are standard error (SE)

Table 2. Estimated Marginalized Mean (EMM) and standard error (SE) are given for each microsite and weather station based on temperature $\left({ }^{\circ} \mathrm{F}\right)$ and solar radiation (lum/ft2) GLM. Confidence Interval used is $95 \%$

\begin{tabular}{|c|c|c|c|c|c|}
\hline Measurement & Microsite/Site & Em mean & SE & Asymp.LCL & Asymp.UCL \\
\hline \multirow{7}{*}{ Temperature $\left({ }^{\circ} \mathrm{F}\right)$} & open & 73.7 & \pm 0.219 & 73.3 & 74.1 \\
\hline & shrub & 73.9 & \pm 0.351 & 73.2 & 74.6 \\
\hline & shrub.surface & 77.0 & \pm 0.417 & 76.2 & 77.8 \\
\hline & square & 72.7 & \pm 0.378 & 71.9 & 73.4 \\
\hline & soil.surface & & & & \\
\hline & triangle & 70.5 & \pm 0.463 & 69.6 & 71.4 \\
\hline & weather.station & 68.3 & \pm 0.872 & 66.6 & 70.0 \\
\hline \multirow{6}{*}{$\begin{array}{l}\text { Solar Radiation } \\
\quad\left(\text { lum/ } / \mathrm{ft}^{2}\right)\end{array}$} & open & 3331.5 & \pm 80.5 & 3174 & 3489 \\
\hline & shrub & 1628 & \pm 129.6 & 1374 & 1882 \\
\hline & soil.surface & 33.9 & \pm 186.8 & -332 & 400 \\
\hline & square & 1675.5 & \pm 138.6 & 1404 & 1947 \\
\hline & triangle & 1861.4 & \pm 171.3 & 1526 & 2197 \\
\hline & weather.station & 16478 & \pm 248.2 & 15992 & 16964 \\
\hline
\end{tabular}



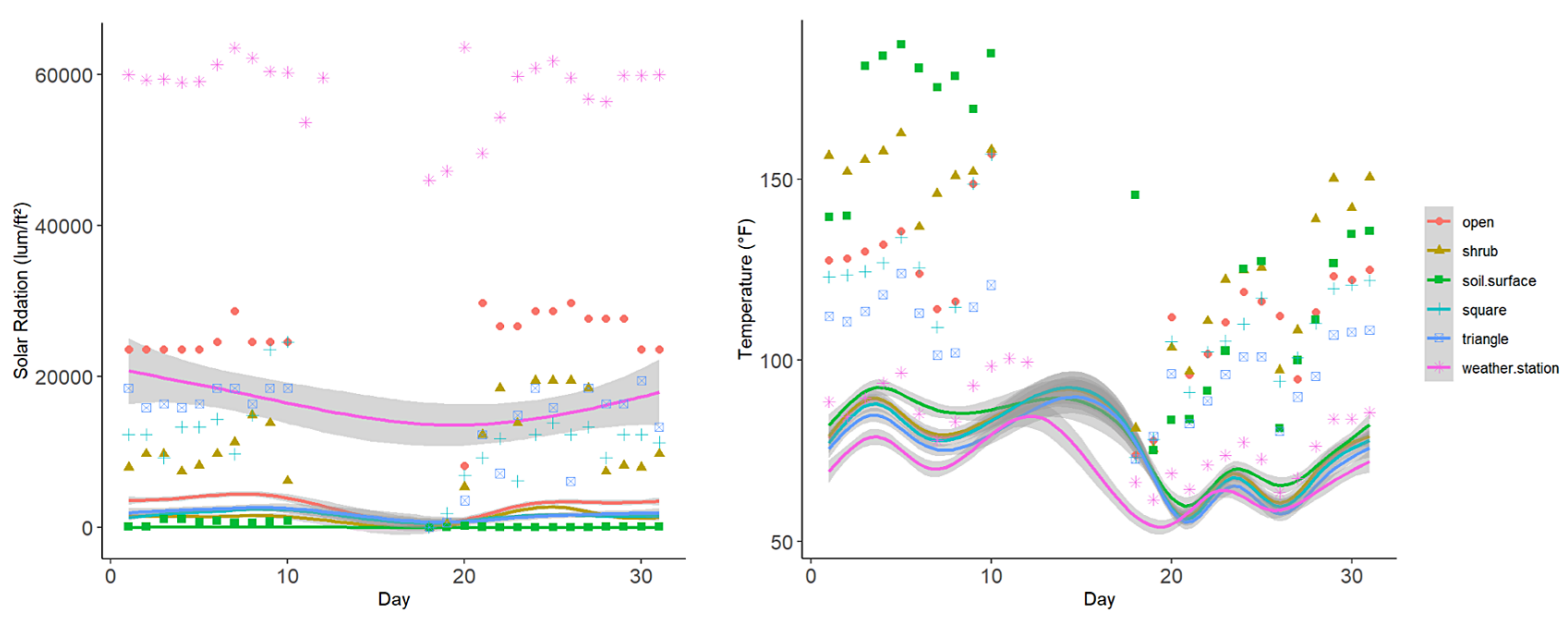

Figure 2. Smoothed conditional mean for temperature $\left({ }^{\circ} \mathrm{F}\right)$ and solar radiation (lum/ft2) over the course of the spring-summer 2019 season recorded at each microsite and retrieved from Los Baños Weather Station. Point shapes represent maximum dailies at each microsite. Confidence interval shown are standard error

(Table 3). Weather-station underestimated micro-climatic temperatures and were significantly cooler than the open gap, shrub, and square microsites (Figure 1 and Table 2, post-hoc test, $\mathrm{p}=0.0001)$ (F and L; Supplementary Appendix). Overall, temperature significantly increased with light intensity (Kendall's tau $=0.281, \mathrm{p}=0.0001$, $\mathrm{N}$; Supplementary Appendix) and this relationship was significantly, positively linear at all microsites but not at triangle $(\mathrm{O}$; Supplementary Appendix, $\mathrm{p}=0.001$ ).

\section{Light intensity effects}

Daily mean light intensities were used to compare between microsites. The shrub microsite experienced the lowest light intensities (EMM $1628 \pm 129.6 \mathrm{lum} / \mathrm{ft}^{2}$ ) followed by square $\left(1675.5 \pm 138.6 \mathrm{lum} / \mathrm{ft}^{2}\right)$ and triangle $(1861 \pm$ $171.3 \mathrm{lum} / \mathrm{ft}^{2}$ ) (Table 2 and Figure 1). The open gap microsites experienced had the highest mean light levels (EMM 3331.5 $\pm 80.5 \mathrm{lum} / \mathrm{ft}^{2}$ ) (Table 2 and Figure 1). Square, triangle, and

Table 3. Spread calculated using variance in temperature and solar radiation at microsites and site. Significant P-values are bolded

\begin{tabular}{|c|c|c|}
\hline Microsite & $\begin{array}{c}\text { Variance } \\
\text { Temperature }\left(\mathrm{s}^{2}\right)\end{array}$ & $\begin{array}{c}\text { Variance Solar } \\
\text { Radiation }\left(\mathrm{s}^{2}\right)\end{array}$ \\
\hline Open & 786.0095 & 51449536.56 \\
\hline Shrub & 1022.394 & 11887055.49 \\
\hline Soil.surface & 955.08566 & 23770.813 \\
\hline Square & 698.6578 & 10107115.06 \\
\hline Triangle & 488.1092 & 28630191.11 \\
\hline Weather.station & 212.2233 & $5.38 \times 10^{8}$ \\
\hline
\end{tabular}

shrub experienced significantly lower light intensities compared to the open gap (Figure 1 and Table 2) (G; Supplementary Appendix; post-hoc test, $p=0.0001)$. The light intensity under the square shelter was significantly lower than the triangle and the shrub (post-hoc $\mathrm{p}=0.0001$; G; Supplementary Appendix). Furthermore, we looked at daily maximum solar radiation and found that the highest sunlight intensities were more often recorded by the weather-station and in the open gap (Figure 2). The relative variance in light experienced varied significantly between the microsites and the weather-station (Table 3, Levene's $\mathrm{F}$-Value $=815.31, \mathrm{p}=0.0001)$. The weather station experienced the highest variance in solar radiation (Table 3) followed by the open gap (Table 3), whilst the triangle, square, and shrub experienced lower variances (Table 3). Solar radiation measured at satellite weather-station was significantly higher than all microsites and the open gap areas (G; Supplementary Appendix; post-hoc test, $\mathrm{p}=0.0001)$.

\section{DISCUSSION}

Shrubs and structural heterogeneity are important components of ecosystems relevant to the conservation and restoration of other plants and animals. A shelter, vegetation, or artificial of any sort in deserts provides amelioration or even just differences in the temperature and light at fine-scales that provides plants and particularly animals with thermal options (Ivey et al. 2020; Attum and Eason 2006). The hypothesis that 

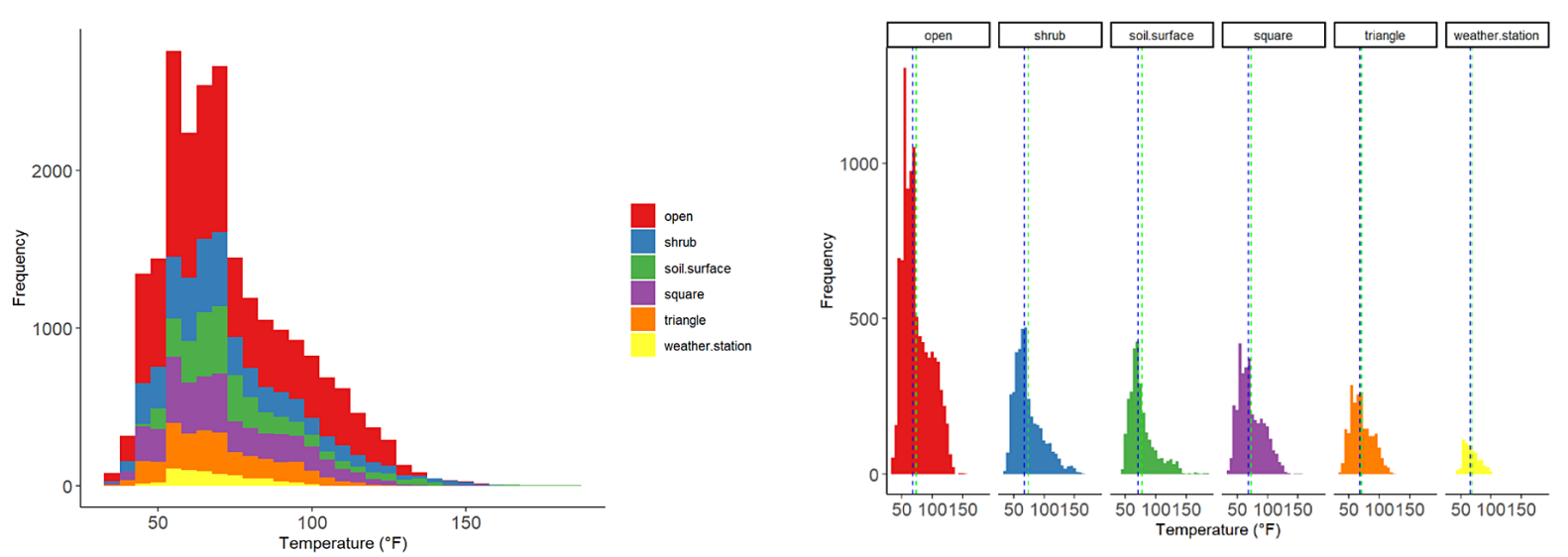

Figure 3. Frequency histogram of temperatures $\left({ }^{\circ} \mathrm{F}\right)$ recorded at each microsite or weather station and combined. Vertical green dashed lines are the mean and the blue dashed lines represent the median

artificial shelters can provide a similar thermal and light habitat to shrub canopies was supported here. Both shapes approximated the ameliorating canopy effects of the nearby Ephedra californica; however, square was most comparable to shrub at cooling as the two microsites did not statistically differ, and both were significantly hotter than triangle. The statistical difference in cooling between triangle and square was only significant under the $90 \%$ blockage. Shelter and shrubs significantly reduced the mean daily solar radiation relative to the open gap. Statistical spread for temperature was greatest in the open gap compared to the shelter and shrub microsites. Daily temperature maxima were also the highest in the open gap. Sunlight experienced under the square canopy was significantly lower compared to shrub or triangle. Moreover, square and triangle experienced the lowest amplitude of variation. We also predicted that micro-climatic variation at microsite level differs from similar sensors at weather stations. Temperatures recorded at weather-station were significantly cooler than onsite level data. Additionally, solar radiation from weather-station was significantly higher than all other microsites (including the open gap) and the low spread experienced under shrubs or artificial canopies strongly suggested amelioration at finescales through buffered variation in climate. This evidence suggests that shelters can provide and important mechanism or tool for stakeholders to provide habitat for plants and animals either as a temporary stepping stone in restoration strategies or as a means to enhance habitat quality through simple and cost effective interventions.

Shrubs typically facilitate plants and animals within their understory. These canopies are able to ameliorate the physical conditions of the understory (Shumway 2000; Filazzola et al. 2017). These effects can influence annual density, species diversity (Kidron 2009) and associations with other taxa (Lortie, Filazzola, and Sotomayor 2016) including pollinators (Braun and Lortie 2019). Our shelters closely emulated the effects shrubs on understory by providing a cooler microhabitat with a lower daily maxima and amplitude of variation for solar radiation. This is consistent with findings of previous studies using artificial shades in drylands to create cooler and moister microhabitats (Smith, Patten, and Monson 1987; Barrow et al. 1996). Temperatures under the square canopy experienced the greatest amelioration effect and had the closest facilitation effect to that of E. californica perhaps because the canopy of structure of a rectangular prism is more analogous the canopy effects of $E$. californica. The structure of the canopy controls the quantity, quality, and temporal distribution of incoming sunlight, and that in turn impacts wind and air movement, and subsequently temperature and precipitation regimes through boundary layer effects (Jennings, Brown, and Sheil 1998). Solar radiation is a direct thermospheric heating source and its effect on pressure differences results in solar wind fluctuations (Knipp, Tobiska, and Emery 2004). In natural vegetation, leaf area index (LAI) is a dimension-less value of the leaf area per unit ground area (Breda 2003). The cooling effect on canopy air temperature and shade effectiveness is directly related to LAI, with species of higher LAI values generally providing a greater cooling effect compared to other species (Tukiran 2016). However, the relationship between LAI an canopy cover is not clear-cut and 
can be more complex than previously thought (Nielsen, Miceli-Garcia, and Lyon 2012). In nondeciduous plants, LAI maybe be more related to branching and twigs, rather the leaf itself, with thicker branching resulting in higher LAIs; therefore, influencing the amount of incoming sunlight (Wilfong, Brown, and Blaser 1967). This can also change light quality in the ratio of red to far red/ blue relevant to other plant species (Kasperbauer 1971) and generate light dappling effect that can influence plants and animals through relatively lower and more variable intensities (Brantley and Young 2010), further influencing direct cooling effects. Similar to vegetation, we suspect that the geometrical structure of a rectangular prism (canopy volume and depth) and sunflecking though shade clothes at $15 \%$ and $50 \%$ most similarly matches the canopy effects and possibly the LAI of E. californica (though, the latter cannot be confirmed since LAI was not measured). The combined effects of shape and shade cloths influence wind movements and increase indirect cooling effect. This suggests that artificial canopies can in fact be used in conjugation with shrubs or in shrub-less areas in order to enhance ecosystem well-being in times of high abiotic stress.

The scale you measure climate is important for plants and animals. We found that mean daily temperatures recorded at the nearby weather-station were significantly lower than microsite level logger data and had less variation compared to shrub and shelter microsite. Moreover, daily maximum temperature recorded by weather station were always lower than all fine-scale level data. A study by Lathlean et al. (2011) reported significantly lower air temperatures when measured via in situ loggers and concluded that coarse-scale data were ineffective at capturing extremes in air temperature variability. Additionally, the ground at Panoche Hills is not completely bare and is, in fact, covered with a thick, dry layer of goldencoloured Mediterranean grasses during the spring and summer periods that reflect light back to the loggers; therefore, increasing the on-site recoded temperature. Desertification from sustained drought periods can decrease vegetation greenness and make surfaces look lighter, lowering the shadowing effect and hence increasing land surface albedo (Ghulam et al. 2007). This is consistent with the idea that dark surfaces typically absorb more incident radiation than light-coloured, high reflectance surfaces (Stuart-Fox, Newton, and Clusella-Trullas 2017). This discrepancy between weather-station and on-site level data goes to demonstrate that locally climate is experienced differently compared to satellite-level data. Hence, it is ecologically vital that managers not only considers coarse-scale climate in conservation practices, but also incorporate micro-climate since only considering station data may be detrimental to the survival of small plants and animals that are more susceptible to temperature fluctuations and thermal exasperation.

\section{Implications}

Micro-environmental variation is a form of habitat and thermal and structural heterogeneity is critical for some animals including ectotherms, in addition to providing refuge (Bauwens, Hertz, and Castilla 1996; Diaz and Cabezas-Diaz 2004). There is an important positive relationship between species richness and environmental heterogeneity, and environmental heterogeneity can also impact community dynamics (Yang et al. 2015). Environmental heterogeneity can increase the potential species of species being able to colonize different microsites (Lundholm 2009). In a way, micro-environmental heterogeneity provides different niches for a variety of species (Kadmon and Allouche 2007) or resources for habitat selection processes (Lortie et al. 2020; Boyce and McDonald 1999). Shelters can function like vegetation in some capacity and thus increase the thermal heterogeneity within a given environment, at least in deserts. In California, climate change is interfering with wildfire regimes and altering biological communities (Bishop et al. 2019). Not only can post-disturbance recovery of vegetation take decades (Berry et al. 2016), but competition and invasion by non-natives are amongst other challenges slowing the recruitment of native vegetation (Bowman et al. 2009, 2011). Hence, the benefit of artificial shelters as a mode of conservation is evident, whilst other efforts are made to re-establish the native community and the natural vegetation has had the time and resources to reemerge. Signs of human-induced climate change is already visible in a variety of ecosystems. Species all around the world face changes in distribution and abundance due to migration and range shift (Midgley et al. 2002). This change will impact the physiology, growth, and productivity of biota (Cannell 1998), as well as their behaviour (Walther, Burga, and Edwards 2001). Given the current rates, it will not be long before species 
can no longer physiologically and behaviourally mitigate the impacts of climate change. Animals such as lizards may already be over-expending energy when trying to thermoregulate (Vickers, Manicom, and Schwarzkopf 2011). This study suggests that shelters offer a mechanism to create climate refuges as a temporary solution or a longterm strategy, and as an effective form of interference for today's every-growing anthropogenic disturbances.

\section{Acknowledgements}

This research was made possible through a Natural Sciences and Engineering Research Council of Canada (NSERC) grant awarded to C.J.L. and the Mitacs Globalink award and York University Faculty of Graduate Studies (FGS) fund granted to N.G. and M.Z.

We are thankful to the BLM for allowing us to conduct research in their land. We are grateful to M. MacDonald for her help in designing the project and editing the manuscript. We thank M. Westphal for his help during field work. We also thank J. Braun, M. Owen, and S. Haas for their feedback on statistical analyses.

\section{REFERENCES}

1. Abatzoglou, John T., and Crystal A. Kolden. 2011. Climate Change in Western US Deserts: Potential for Increased Wildfire and Invasive Annual Grasses. Rangeland Ecology \& Management 64 (5): 471-78. https://doi.org/10.2111/REM-D-09-00151.1.

2. Abduwasit, Ghulam, Li Zhaoliang, Qi Qiming, and Tong Qingxi. 2007. Exploration of the Spectral Space Based on Vegetation Index and Albedo for Surface Drought Estimation. Journal of Applied Remote Sensing 1 (1): 013529. https://doi. org/10.1117/1.2784792.

3. Allen, Michael F., C.W. Barrows, Michael D. Bell, G Darrel Jenerette, Robert F. Johnson, and Edith B. Allen. 2014. Threats to California's Desert Ecosystems. 42 (2).

4. Armas, Cristina, Ramón Ordiales, and Francisco I. Pugnaire. 2004. Measuring plant interactions: a new comparative index. Ecology 85 (10): 2682-86. https://doi.org/10.1890/03-0650.

5. Attum, Omar A., and Perri K. Eason. 2006. Effects of Vegetation Loss on a Sand Dune Lizard. Edited by Ribic. Journal of Wildlife Management 70 (1): 27-30. https://doi.org/10.2193/0022-541X(2006)7 $0[27:$ EOVLOA $] 2.0 . \mathrm{CO} ; 2$.
6. Bachelet, D., K. Ferschweiler, T. Sheehan, and J. Strittholt. 2016. Climate Change Effects on Southern California Deserts. Journal of Arid Environments 127 (April): 17-29. https://doi.org/10.1016/j. jaridenv.2015.10.003.

7. Barrow, Jerry R., E. Durant MacArthur, Ronald E. Sosebee, and Robin J. Tausch. 1996. Proceedings: Scrubland Ecosystem Dynamics in a Changing Environment. Intermountain Research Station.

8. Barrows, C.W. 2011. Sensitivity to Climate Change for Two Reptiles at the Mojave-Sonoran Desert Interface. Journal of Arid Environments 75 (7): 62935. https://doi.org/10.1016/j.jaridenv.2011.01.018.

9. Bauwens, Dirk, Paul E. Hertz, and Aurora M. Castilla. 1996. Thermoregulation in a Lacertid Lizard: The Relative Contributions of Distinct Behavioral Mechanisms. Ecology 77 (6): 1818-30. https://doi. org/10.2307/2265786.

10. Berry, Kristin H., James F. Weigand, Timothy A. Gowan, and Jeremy S. Mack. 2016. Bidirectional Recovery Patterns of Mojave Desert Vegetation in an Aqueduct Pipeline Corridor after 36 Years: I. Perennial Shrubs and Grasses. Journal of Arid Environments 124 (January): 413-25. https://doi. org/10.1016/j.jaridenv.2015.03.004.

11. Bishop, Tara B. B., Richard A. Gill, Brock R. McMillan, and Samuel B. St. Clair. 2019. Fire, Rodent Herbivory, and Plant Competition: Implications for Invasion and Altered Fire Regimes in the Mojave Desert. Oecologia, November. https://doi. org/10.1007/s00442-019-04562-2.

12. Bowman, D.M.J.S., J.K. Balch, P. Artaxo, W.J. Bond, J.M. Carlson, M.A. Cochrane, C.M. D'Antonio, et al. 2009. Fire in the Earth System. Science 324 (5926): 481-84. https://doi.org/10.1126/science.1163886.

13. Bowman, David M.J.S., Jennifer Balch, Paulo Artaxo, William J. Bond, Mark A. Cochrane, Carla M. D’Antonio, Ruth DeFries, et al. 2011. The Human Dimension of Fire Regimes on Earth: The Human Dimension of Fire Regimes on Earth. Journal of Biogeography 38 (12): 2223-36. https://doi. org/10.1111/j.1365-2699.2011.02595.x.

14. Boyce, Mark S., and Lyman L. McDonald. 1999. Relating Populations to Habitats Using Resource Selection Functions. Trends in Ecology \& Evolution 14 (7): 268-72. https://doi.org/10.1016/ S0169-5347(99)01593-1.

15. Brantley, Steven T., and Donald R. Young. 2010. Linking Light Attenuation, Sunflecks, and Canopy Architecture in Mesic Shrub Thickets. Plant Ecology 206 (2): 225-36. https://doi.org/10.1007/ s11258-009-9637-9.

16. Braun, Jenna, and Christopher J. Lortie. 2019. Finding the Bees Knees: A Conceptual Framework and Systematic Review of the Mechanisms of Pollinator-Mediated Facilitation. Perspectives in Plant 
Ecology, Evolution and Systematics 36 (February): 33-40. https://doi.org/10.1016/j.ppees.2018.12.003.

17. Breda, N.J.J. 2003. Ground-Based Measurements of Leaf Area Index: A Review of Methods, Instruments and Current Controversies. Journal of Experimental Botany 54 (392): 2403-17. https://doi.org/10.1093/ jxb/erg263.

18. Brooks, Matthew. 1999. Effects of Protective Fencing on Birds, Lizards, and Black-Tailed Hares in the Western Mojave Desert. Environmental Management 23 (3): 387-400. https://doi.org/10.1007/ s002679900194.

19. Cannell, M. 1998. UK Conifer Forests May Be Growing Faster in Response to Increased N Deposition, Atmospheric $\mathrm{CO} 2$ and Temperature. Forestry 71 (4): 277-96. https://doi.org/10.1093/ forestry/71.4.277.

20. Cowling, R.M., R.L. Pressey, A.T. Lombard, P.G. Desmet, and A.G. Ellis. 1999. "From Representation to Persistence: Requirements for a Sustainable System of Conservation Areas in the Species-Rich Mediterranean-Climate Desert of Southern Africa. Diversity Distributions 5 (1-2): 51-71. https://doi. org/10.1046/j.1472-4642.1999.00038.x.

21. Diaz, J.A., and S. Cabezas-Diaz. 2004. Seasonal Variation in the Contribution of Different Behavioural Mechanisms to Lizard Thermoregulation. Functional Ecology 18 (6): 867-75. https://doi. org/10.1111/j.0269-8463.2004.00916.x.

22. Eliason, Scott A., and Edith B. Allen. 1997. Exotic Grass Competition in Suppressing Native Shrubland Re-Establishment. Restoration Ecology 5 (3): 245-55. https://doi. org/10.1046/j.1526-100X.1997.09729.x.

23. Elmqvist, Thomas, ed. 2013. Urbanization, Biodiversity and Ecosystem Services: Challenges and Opportunities: A Global Assessment ; a Part of the Cities and Biodiversity Outlook Project. Springer Open. Dordrecht: Springer.

24. English, N.B., J.F. Weltzin, A. Fravolini, L. Thomas, and D.G. Williams. 2005. The Influence of Soil Texture and Vegetation on Soil Moisture under Rainout Shelters in a Semi-Desert Grassland. Journal of Arid Environments 63 (1): 324-43. https://doi. org/10.1016/j.jaridenv.2005.03.013.

25. Filazzola, Alessandro, and Christopher J. Lortie. 2014. A Systematic Review and Conceptual Framework for the Mechanistic Pathways of Nurse Plants: A Systematic Review of Nurse-Plant Mechanisms. Global Ecology and Biogeography 23 (12): 133545. https://doi.org/10.1111/geb.12202.

26. Filazzola, Alessandro, Michael Westphal, Michael Powers, Amanda Rae Liczner, Deborah A. (Smith) Woollett, Brent Johnson, and Christopher J. Lortie. 2017. Non-Trophic Interactions in Deserts: Facilitation, Interference, and an Endangered Lizard
Species. Basic and Applied Ecology 20 (May): 51-61. https://doi.org/10.1016/j.baae.2017.01.002.

27. Finch, Deborah M. 2012. Climate Change in Grasslands, Shrublands, and Deserts of the Interior American West: A Review and Needs Assessment. RMRS-GTR-285. Ft. Collins, CO: U.S. Department of Agriculture, Forest Service, Rocky Mountain Research Station. https://doi.org/10.2737/ RMRS-GTR-285.

28. Flores, Joel, and Enrique Jurado. 2003. Are Nurse-protégé Interactions More Common among Plants from Arid Environments? Journal of Vegetation Science 14 (6): 911-16. https://doi. org/10.1111/j.1654-1103.2003.tb02225.x.

29. Fuhlendorf, Samuel D., Richard W. S. Fynn, Devan Allen McGranahan, and Dirac Twidwell. 2017. Heterogeneity as the Basis for Rangeland Management. In Rangeland Systems, edited by David D. Briske, 169-96. Springer Series on Environmental Management. Cham: Springer International Publishing. https://doi.org/10.1007/978-3-319-46709-2_5.

30. Germano, David J., Galen B. Rathbun, Lawrence R. Saslaw, Brian L. Cypher, Ellen A. Cypher, and Larry M. Vredenburgh. 2011. The San Joaquin Desert of California: Ecologically Misunderstood and Overlooked. Natural Areas Journal 31 (2): 138-47. https://doi.org/10.3375/043.031.0206.

31. Ghazian, Nargol. 2020. Microclimatic Amelioration in a California Desert System: Artificial Shelters versus Shrub Canopy-Statistical Analyses Codes (version 1). Zenodo. https://doi.org/10.5281/ ZENODO.3932254.

32. Ghazian, Nargol, Mario Zuliani, and Christopher Lortie. 2020. Microclimatic Amelioration in a California Desert System: Artificial Shelters versus Shrub Canopy-Macro-Micro Data. figshare. https:// doi.org/10.6084/M9.FIGSHARE.12616451.

33. Gherardi, Laureano A., and Osvaldo E. Sala. 2013. Automated Rainfall Manipulation System: A Reliable and Inexpensive Tool for Ecologists. Ecosphere 4 (2): art18. https://doi.org/10.1890/ES12-00371.1.

34. Guerreiro, Selma B., Chris Kilsby, and Hayley J. Fowler. 2017. Assessing the Threat of Future Megadrought in Iberia: Assessing the threat of future megadrought in Iberia. International Journal of Climatology 37 (15): 5024-34. https://doi.org/10.1002/joc.5140.

35. Hadley, Neil F. 1970. Micrometeorology and Energy Exchange in Two Desert Arthropods. Ecology 51 (3): 434-44. https://doi.org/10.2307/1935378.

36. Holzapfel, Claus, and Bruce E. Mahall. 1999. Bidirectional facilitation and interference between shrubs and annuals in the mojave desert. Ecology 80 (5): 1747-61. https://doi.org/10.1890/0012-965 8(1999)080[1747:BFAIBS]2.0.CO;2.

37. Hoskin Scientific. 2020. HOBO Pendant Temperature/Light 8K Data Logger. 2020. https://shoponset. 
hoskin.ca/products/hobo-pendant-temperaturelight-8k-data-logger?variant $=42959120400$.

38. Irwin, Mitchell T., Patricia C. Wright, Christopher Birkinshaw, Brian L. Fisher, Charlie J. Gardner, Julian Glos, Steven M. Goodman, et al. 2010. Patterns of Species Change in Anthropogenically Disturbed Forests of Madagascar. Biological Conservation 143 (10): 2351-62. https://doi.org/10.1016/j. biocon.2010.01.023.

39. Ivey, Kathleen N, Margaret Cornwall, Hayley Crowell, Nargol Ghazian, Emmeleia Nix, Malory Owen, Mario Zuliani, Christopher J. Lortie, Michael Westphal, and Emily Taylor. 2020. Thermal Ecology of the Federally Endangered Blunt-Nosed Leopard Lizard (Gambelia Sila). Edited by Steven Cooke. Conservation Physiology 8 (1): coaa014. https://doi.org/10.1093/conphys/coaa014.

40. Jennings, S.B., N.D. Brown, and D. Sheil. 1998. Assesing Forest Canopies and Understory Illumination: Canopy Closure, Canopy Cover and Other Measures. 72 (1): 59-73.

41. Kadmon, Ronen, and Omri Allouche. 2007. Integrating the Effects of Area, Isolation, and Habitat Heterogeneity on Species Diversity: A Unification of Island Biogeography and Niche Theory. The American Naturalist 170 (3): 443-54. https://doi. org/10.1086/519853.

42. Kasperbauer, M.J. 1971. Spectral Distribution of Light in a Tobacco Canopy and Effects of Endof-Day Light Quality on Growth and Development. Plant Physiology 47 (6): 775-78. https://doi. org/10.1104/pp.47.6.775.

43. Kidron, Giora J. 2009. The Effect of Shrub Canopy upon Surface Temperatures and Evaporation in the Negev Desert. Earth Surface Processes and Landforms 34 (1): 123-32. https://doi.org/10.1002/esp.1706.

44. Knipp, D.J., W.K. Tobiska, and B.A. Emery. 2004. Direct and Indirect Thermospheric Heating Sources for Solar Cycles 21-23. Solar Physics 224 (1-2): 495-505. https://doi.org/10.1007/ s11207-005-6393-4.

45. Kogan, Felix, and Wei Guo. 2015. 2006-2015 Mega-Drought in the Western USA and Its Monitoring from Space Data. Geomatics, Natural Hazards and Risk 6 (8): 651-68. https://doi.org/10.1080/19475 705.2015.1079265.

46. Lathlean, Ja, Dj Ayre, and Te Minchinton. 2011. Rocky Intertidal Temperature Variability along the Southeast Coast of Australia: Comparing Data from in Situ Loggers, Satellite-Derived SST and Terrestrial Weather Stations. Marine Ecology Progress Series 439 (October): 83-95. https://doi.org/10.3354/ meps09317.

47. Lenth, R., and M. Herve. 2019. Emmeans, Estimated Marginal Means, Aka Least-Squared Means. (version 1.1.2).
48. Li, Yan, Eugenia Kalnay, Safa Motesharrei, Jorge Rivas, Fred Kucharski, Daniel Kirk-Davidoff, Eviatar Bach, and Ning Zeng. 2018. Climate Model Shows Large-Scale Wind and Solar Farms in the Sahara Increase Rain and Vegetation. Science 361 (6406): 1019-22. https://doi.org/10.1126/science.aar5629.

49. Lortie, Christopher J., Jenna Braun, Michael Westphal, Taylor Noble, Mario Zuliani, Emmeleia Nix, Nargol Ghazian, Malory Owen, and H. Scott Butterfield. 2020. Shrub and Vegetation Cover Predict Resource Selection Use by an Endangered Species of Desert Lizard. Scientific Reports 10 (1): 4884. https://doi.org/10.1038/s41598-020-61880-9.

50. Lortie, Christopher J., Alessandro Filazzola, and Diego A. Sotomayor. 2016. Functional Assessment of Animal Interactions with Shrub-Facilitation Complexes: A Formal Synthesis and Conceptual Framework. Edited by Richard Michalet. Functional Ecology 30 (1): 41-51. https://doi. org/10.1111/1365-2435.12530.

51. Lortie, Christopher J., Eva Gruber, Alex Filazzola, Taylor Noble, and Michael Westphal. 2018. The Groot Effect: Plant Facilitation and Desert Shrub Regrowth Following Extensive Damage."Ecology and Evolution 8 (1): 706-15. https://doi.org/10.1002/ ece3.3671.

52. Lovich, Jeffrey E., and Joshua R. Ennen. 2011. Wildlife Conservation and Solar Energy Development in the Desert Southwest, United States. BioScience 61 (12): 982-92. https://doi.org/10.1525/ bio.2011.61.12.8.

53. Lundholm, Jeremy T. 2009. Plant Species Diversity and Environmental Heterogeneity: Spatial Scale and Competing Hypotheses. Journal of Vegetation Science 20 (3): 377-91. https://doi. org/10.1111/j.1654-1103.2009.05577.x.

54. Marion, G.M., G.H.R. Henry, D.W. Freckman, J. Johnstone, G. Jones, M.H. Jones, E. Lévesque, et al. 1997. Open-Top Designs for Manipulating Field Temperature in High-Latitude Ecosystems. Global Change Biology 3 (S1): 20-32. https://doi. org/10.1111/j.1365-2486.1997.gcb136.x.

55. McCluney, Kevin E., Jayne Belnap, Scott L. Collins, Angélica L. González, Elizabeth M. Hagen, J. Nathaniel Holland, Burt P. Kotler, Fernando T. Maestre, Stanley D. Smith, and Blair O. Wolf. 2012. Shifting Species Interactions in Terrestrial Dryland Ecosystems under Altered Water Availability and Climate Change. Biological Reviews 87 (3): 563-82. https:// doi.org/10.1111/j.1469-185X.2011.00209.x.

56. Meyer, Susan E., and Burton K. Pendleton. 2005. Factors Affecting Seed Germination and Seedling Establishment of a Long-Lived Desert Shrub (Coleogyne Ramosissima: Rosaceae). Plant Ecology 178 (2): 171-87. https://doi.org/10.1007/ s11258-004-3038-x. 
57. Midgley, G.F., L. Hannah, D. Millar, M.C. Rutherford, and L.W. Powrie. 2002. Assessing the Vulnerability of Species Richness to Anthropogenic Climate Change in a Biodiversity Hotspot. Global Ecology and Biogeography 11 (6): 445-51. https:// doi.org/10.1046/j.1466-822X.2002.00307.x.

58. Mills, L. Scott, and Daniel F. Doak. 1993. The Keystone-Species Concept in Ecology and Conservation. BioScience 43 (4): 219-24. https://doi. org/10.2307/1312122.

59. Miriti, maria n., s. Joseph wright, and henry f. Howe. 2001. The effects of neighbors on the demography of a dominant desert shrub (Ambrosia dumosa). Ecological Monographs 71 (4): 491-509. https:// doi.org/10.1890/0012-9615(2001)071[0491:TEO NOT]2.0.CO;2.

60. Morris, M.G. 2000. The Effects of Structure and Its Dynamics on the Ecology and Conservation of Arthropods in British Grasslands. Biological Conservation 95 (2): 129-42. https://doi.org/10.1016/ S0006-3207(00)00028-8.

61. Munguia-Vega, Adrian, Ricardo Rodriguez-Estrella, William W. Shaw, and Melanie Culver. 2013. Localized Extinction of an Arboreal Desert Lizard Caused by Habitat Fragmentation. Biological Conservation 157 (January): 11-20. https://doi. org/10.1016/j.biocon.2012.06.026.

62. Nabhan, Gary Paul. 2013. Growing Food in a Hotter, Drier Land: Lessons from Desert Farmers on Adapting to Climate Uncertainty. White River Junction, Vt: Chelsea Green Pub.

63. Nielsen, David C., Juan J. Miceli-Garcia, and Drew J. Lyon. 2012. Canopy Cover and Leaf Area Index Relationships for Wheat, Triticale, and Corn. Agronomy Journal 104 (6): 1569-73. https://doi. org/10.2134/agronj2012.0107n.

64. Nopper, Joachim, Jana C. Riemann, Katja Brinkmann, Mark-Oliver Rödel, and Jörg U. Ganzhorn. 2018. Differences in Land Cover - Biodiversity Relationships Complicate the Assignment of Conservation Values in Human-Used Landscapes. Ecological Indicators 90 (July): 112-19. https://doi. org/10.1016/j.ecolind.2018.02.004.

65. Olden, Julian D., N. LeRoy Poff, and Kevin R. Bestgen. 2008. Trait synergisms and the rarity, extirpation, and extinction risk of desert fishes. Ecology 89 (3): 847-56. https://doi.org/10.1890/06-1864.1.

66. R Core Team. 2020. R (version 4.0.0).

67. Richards, Shane A., Mark J. Whittingham, and Philip A. Stephens. 2011. Model Selection and Model Averaging in Behavioural Ecology: The Utility of the IT-AIC Framework. Behavioral Ecology and Sociobiology 65 (1): 77-89. https://doi.org/10.1007/ s00265-010-1035-8.

68. Sankey, Joel B., Sujith Ravi, Cynthia S. A. Wallace, Robert H. Webb, and Travis E. Huxman. 2012.
Quantifying soil surface change in degraded drylands: shrub encroachment and effects of fire and vegetation removal in a desert grassland: Shrub encroachment, fire and soil change. Journal of Geophysical Research: Biogeosciences 117 (G2): n/an/a. https://doi.org/10.1029/2012JG002002.

69. Sawyer, John O., Todd Keeler-Wolf, and Julie Evens. 2009. A Manual of California Vegetation. Sacramento, Calif:: California Native Plant Society Press. http://books.google.com/ books?id=y401AQAAMAAJ.

70. Schultz, B.B. 1985. Levene's Test for Relative Variation. Systematic Biology 34 (4): 449-56. https:// doi.org/10.1093/sysbio/34.4.449.

71. Schützenmeister, A., U. Jensen, and H.-P. Piepho. 2012. Checking Normality and Homoscedasticity in the General Linear Model Using Diagnostic Plots. Communications in Statistics - Simulation and Computation 41 (2): 141-54. https://doi.org/10.10 $80 / 03610918.2011 .582560$.

72. Shrode, Joy B., and Shelby D. Gerking. 1977. Effects of Constant and Fluctuating Temperatures on Reproductive Performance of a Desert Pupfish, Cyprinodon n. Nevadensis. Physiological Zoology 50 (1): 1-10. https://doi.org/10.1086/ physzool.50.1.30155710.

73. Shumway, Scott W. 2000. Facilitative Effects of a Sand Dune Shrub on Species Growing beneath the Shrub Canopy. 124: 138-48. https://doi. org/10.1007/s004420050033.

74. Smith, SD, DT Patten, and RK Monson. 1987. Effects of Artificially Imposed Shade on Sonoran Desert Ecosystem: Microclimate Andvegetation. 13: $65-82$.

75. Sonnentag, O., J. Talbot, J.M. Chen, and N.T. Roulet. 2007. Using Direct and Indirect Measurements of Leaf Area Index to Characterize the Shrub Canopy in an Ombrotrophic Peatland. Agricultural and Forest Meteorology 144 (3-4): 200-212. https://doi. org/10.1016/j.agrformet.2007.03.001.

76. Sotomayor, Diego A., and Taly Dawn Drezner. 2019. Dominant plants alter the microclimate along a fog gradient in the atacama desert. Plant Ecology 220 (4-5): 417-32. https://doi.org/10.1007/ s11258-019-00924-1.

77. Stuart, John David, and John O. Sawyer. 2001. Trees and Shrubs of California. California Natural History Guides 62. Berkeley: University of California Press.

78. Stuart-Fox, Devi, Elizabeth Newton, and Susana Clusella-Trullas. 2017. Thermal Consequences of Colour and Near-Infrared Reflectance. Philosophical Transactions of the Royal Society B: Biological Sciences 372 (1724): 20160345. https://doi. org/10.1098/rstb.2016.0345.

79. Thorhallsdottir, Thora Ellen. 1990. The Dynamics of a Grassland Community: A Simultaneous 
Investigation of Spatial and Temporal Heterogeneity at Various Scales. The Journal of Ecology 78 (4): 884. https://doi.org/10.2307/2260941.

80. Throop, Heather L., Lara G. Reichmann, Osvaldo E. Sala, and Steven R. Archer. 2012. Response of Dominant Grass and Shrub Species to Water Manipulation: An Ecophysiological Basis for Shrub Invasion in a Chihuahuan Desert Grassland. Oecologia 169 (2): 373-83. https://doi.org/10.1007/ s00442-011-2217-4.

81. Tukiran, Julia Md. 2016. Cooling effects of two types of tree canopy shape in Penang, Malaysia. International Journal of Geomate. https://doi. org/10.21660/2016.24.1262.

82. Walther, G.-R., Conradin A. Burga, and Peter J. Edwards, eds. 2001. 'Fingerprints' of Climate Change: Adapted Behaviour and Shifting Species Ranges. New York: Kluwer Academic/Plenum Publishers.

83. Wang, Chao, Chuan Yan Zhao, ZhongLin Xu, Yang Wang, and HuanHua Peng. 2013. Effect of Vegetation on Soil Water Retention and Storage in a Semi-Arid Alpine Forest Catchment. Journal of Arid Land 5 (2): 207-19. https://doi.org/10.1007/ s40333-013-0151-5.
84. Webb, Robert H., and Steven S. Stielstra. 1979. Sheep Grazing Effects on Mojave Desert Vegetation and Soils. Environmental Management 3 (6): 517-29. https://doi.org/10.1007/BF01866321.

85. Wilfong, R. T., R. H. Brown, and R. E. Blaser. 1967. Relationships Between Leaf Area Index and Apparent Photosynthesis in Alfalfa (Medicago Sativa L.) and Ladino Clover (Trifolium Repens L.). Crop Science 7 (1): 27-30. https://doi.org/10.2135/cropscil 967.0011183X000700010010x.

86. Williams, M.A.J. 2014. Climate Change in Deserts: Past, Present and Future. New York, NY, USA: Cambridge University Press.

87. Yahdjian, Laura, and Osvaldo E. Sala. 2002. A Rainout Shelter Design for Intercepting Different Amounts of Rainfall. Oecologia 133 (2): 95-101. https://doi.org/10.1007/s00442-002-1024-3.

88. Yang, Zhiyong, Xueqi Liu, Mohua Zhou, Dexiecuo Ai, Gang Wang, Youshi Wang, Chengjin Chu, and Jeremy T. Lundholm. 2015. The Effect of Environmental Heterogeneity on Species Richness Depends on Community Position along the Environmental Gradient. Scientific Reports 5 (1): 15723. https:// doi.org/10.1038/srep15723. 